\title{
A BNCC E O ENSINO RELIGIOSO EM TEMPOS DE RELAÇÕES DE PODER E INTERESSES OCULTOS
}

\author{
Rafael Marques Gonçalves \\ Universidade Federal do Acre - UFAC \\ Talita Pereira de Almeida \\ Universidade Federal do Acre - UFAC
}

\begin{abstract}
Resumo
O presente artigo é resultado de um estudo bibliográfico e documental que teve como objetivo analisar a Base Nacional Comum Curricular enquanto uma política educacional, bem como a inclusão da disciplina de Ensino Religioso no texto da BNCC, refletindo sobre o significado disso e suas consequentes implicações. Lembrando que, o Ensino Religioso é mais do que aparenta ser, isto é, um componente curricular em escolas. Por trás dele se oculta uma dialética entre a secularização e laicidade no interior de contextos históricos, culturais e políticos. Buscamos dar conta de uma breve reflexão em torno das políticas educacionais, analisando o contexto político em que vivemos para que possamos compreender os claros conflitos existentes em torno dessas políticas, situando a BNCC enquanto um campo de interesses. Utilizando como referentes analíticos as contribuições de Apple; Hofling; Offe; Lessard e Ball. Por conseguinte, analisamos o Ensino Religioso enquanto disciplina, seus aspectos legais, e buscamos compreendê-lo tendo em vista que se trata de um ensino problemático, visto que envolve o necessário distanciamento do Estado Laico ante o particularismo próprio dos credos religiosos. Todas essas discussões se fazem necessárias dentro de um contexto de um governo conservador, com uma política neoliberal cujos interesses estão se tornando cada vez mais claros com a retirada de direitos fundamentais e o desmonte da educação pública, gratuita, de qualidade e laica para todos.
\end{abstract}

Palavras-chave: BNCC; Política Educacional; Currículo; Ensino Religioso; Laicidade.

\begin{abstract}
This article is the result of a bibliographic and documentary study that aimed to analyze the Common National Curricular Base as an educational policy, as well as the inclusion of the subject of Religious Education in the text of the BNCC, reflecting on the meaning of this and its consequences. implications. Recalling that, Religious Education is more than appears to be, that is, a curricular component in schools. Behind it hides a dialectic between secularization and secularism within historical, cultural and political contexts. We seek to give a brief reflection on educational policies, analyzing the political context in which we live so that we can understand the clear conflicts that exist around these policies, situating the BNCC as a field of interest. Using as analytical referents contributions Apple; Hofling; Offe; Lessard and Ball. Therefore, we analyze Religious Education as a discipline, its legal aspects, and seek to understand it in view of the fact that it is a problematic teaching as it involves the necessary distancing of the secular state from the particularism of religious beliefs. All of these discussions are necessary in the context of a conservative government, with a neoliberal policy whose interests are becoming increasingly clear with the withdrawal of fundamental rights and the dismantling of free, quality, secular public education for all.
\end{abstract}

Keywords: BNCC; Educational politics; Curriculum; Religious education; Secularity.

ISSN 1645-1384 (online) www.curriculosemfronteiras.org 


\section{Introdução}

No início da década de 1980, com o processo de redemocratização do país, os estudos sobre as políticas públicas passaram a ter destaque e começaram a se fortalecer enquanto um importante campo de investigação. Apple (2002) ressalta que poder de persuasão das políticas neoliberais que vem orientando mudanças e que tem influenciado globalmente as políticas educacionais, promove ainda mais desigualdades, visto que atinge toda a realidade social e repercute nos processos de produção do conhecimento.

De acordo com Hofling (2001), as políticas públicas são entendidas como "Estado em ação” como a autora coloca, ou seja, o Estado implantando um projeto de governo, essas são as chamadas políticas públicas. E as políticas sociais (como a educação) se referem a ações que determinam o padrão social implementado pelo Estado, visando a diminuição das desigualdades estruturais produzidas pelo desenvolvimento socioeconômico.

A autora coloca que as políticas sociais e a educação se situam no interior de um tipo particular de Estado. São formas de interferência do Estado, visando a manutenção das relações sociais de determinada formação social. Porém, de que relações sociais estamos falando? Quais os grupos que se beneficiam com tais políticas? São questionamentos que surgem ao pesquisarmos sobre o contexto de influência dessas políticas.

Neste contexto de políticas públicas sociais, surge a BNCC - A Base Nacional Comum Curricular $^{1}$, como uma ação da política educacional. Um documento normativo que define o conjunto de aprendizagens essenciais que todos os alunos devem desenvolver ao longo das etapas e modalidades da Educação Básica, ou seja, é o documento norteador da elaboração dos currículos e se configura como uma política pública.

Precisamos compreender que a BNCC é considerada uma exigência do sistema educacional brasileiro pela LDB - Lei de Diretrizes e Bases da Educação Nacional (9.934/96), pelas Diretrizes Curriculares Nacionais Gerais da Educação Básica (2009) e pelo Plano Nacional de Educação - PNE (2014).

É nesse contexto que passamos a compreender que existem relações de poder claras envolvidas nesse processo. Os currículos têm forte poder de definir potencialidades para que os sujeitos em formação sejam capazes de atender às expectativas dos modelos que lhe foram definidos.

A construção de bases gerais para a elaboração dos currículos da escola básica tem sido uma preocupação dos órgãos diretores da educação em diferentes momentos da história da educação nacional, se tornando mais recorrente a partir do final da década de 1990. As razões para essa preocupação são várias, mas de acordo com Gontijo (2015), dependem do contexto sociopolítico, econômico e educacional, mas, que de modo geral, todas as propostas partem da necessidade de mudanças vislumbradas por esses órgãos que visaram, de algum modo, à democratização da educação e à modernização do ensino.

E dentro desse contexto, apesar de ser previsto pela Constituição Federal da República de 1988 como disciplina facultativa no Ensino Fundamental, o Ensino Religioso (ER) foi 
inserido na BNCC com conteúdos precisos para cada um dos nove anos. E não foi por acaso que isso aconteceu, isto é, uma disciplina facultativa especificada e detalhada no currículo.

Segundo o Observatório da Laicidade na Educação, tal fato aconteceu por causa da convivência de dirigentes e técnicos da Secretaria de Educação Básica, do Ministério da Educação com o Fórum Nacional Permanente do Ensino Religioso, instituição de origem católica, que coopta alguns adeptos de outras religiões cristãs, e atua como grupo de interesse junto as secretarias de educação de estados e municípios. Assim, neste artigo analisamos a Base Nacional Comum Curricular do $\mathrm{ER}^{2}$ enquanto uma política educacional, bem como a inclusão da disciplina de Ensino Religioso no texto da BNCC, refletindo sobre o significado disso e suas consequentes implicações.

\section{Estado, Políticas Educacionais e a Nova Aliança Conservadora}

De acordo com Hofling (2001), o Estado deve ser entendido como o conjunto de instituições permanentes, como: órgãos legislativos, tribunais, exército e outras que não formam um bloco monolítico necessariamente, mas que possibilitam a ação do governo. E Governo, devendo ser entendido como o conjunto de programas e projetos que parte da sociedade, como: políticos, técnicos, organismos da sociedade civil e outros, propõe para a sociedade como um todo, configurando-se a orientação política de um determinado governo que assume e desempenha as funções de Estado por um determinado período.

O desenvolvimento do Estado, segundo Offe (1985), é determinado pelos seguintes critérios: promoção da paz social; promoção dos direitos da cidadania; ação ativa da cidadania como fonte de sua legitimidade; distribuição de recursos e a administração da sociedade, nos termos do Estado de bem-estar Keynesiano, ou seja, pela perspectiva de classe. Para ele, um Estado capitalista não pensa em transformação social, pois visa qualificar a mão de obra de maneira permanente para o mercado, e, através de tal política e programas sociais, procura manter sob controle parcelas da população não inseridas no processo produtivo.

A política neoliberal significa "menos Estado e mais mercado" e sua concepção de Estado e Governo, são voltadas fundamentalmente para a crítica das teses de Keynes, ou seja, a ideia de Estado de bem-estar social. Para esse grupo neoliberal, as políticas públicas sociais são ações do Estado na tentativa de regular os desequilíbrios gerados pelo desenvolvimento da acumulação capitalista que são consideradas um dos maiores entraves a este mesmo desenvolvimento e seus responsáveis.

Ao compreendermos o conceito de uma política neoliberal, fica claro que eles não defendem a responsabilidade do Estado em relação ao oferecimento de educação pública a todo cidadão, em termos universalizantes, de maneira padronizada, afinal de contas, não é do interesse deles uma mudança nas relações sociais de classe. O que o pobre precisa é aprender o básico para se tornar mão de obra neste país, a educação política, econômica e social fica para quem comanda os meios de produção. E de acordo com as últimas notícias, acreditamos 
que infelizmente esse é o pensamento predominante na atual política brasileira em relação a educação pública.

As teorias neoliberais dizem que as políticas devem proporcionar o direito às famílias de livre escolha em relação ao tipo de educação desejada para os seus filhos, por meio deste caminho seria possível estimular a competição entre os serviços oferecidos no mercado, mantendo-se o padrão da qualidade deles. Para que esse livre exercício de escolha aconteça, se faz necessário um processo de descentralização da educação, ou seja, tirar do Estado essa responsabilidade e transferir para outras instituições, neste caso aqui, as privadas, com o objetivo de reduzir os gastos públicos. Ou seja, a educação não é vista como investimento no desenvolvimento do país, não no Brasil.

Os neoliberais postulam para a política educacional, ações descentralizadas do Estado, articuladas com a iniciativa privada, a fim de preservar a possibilidade de cada um se colocar, de acordo com seus próprios méritos e possibilidades, em seu lugar adequado na estrutura social (Hofling, 2001).

\subsection{Políticas Educacionais e a Base Nacional Comum Curricular (BNCC)}

De acordo com Lessard (2016), a intenção de uma política educacional pode ser clara e visível, ou então obscura e camuflada. Conhecendo a intenção de uma política educacional, poderá ser compreendido outro aspecto que a envolve - o poder. Esse aspecto da elaboração da política educacional permite associá-la, para uma melhor interpretação, a duas antiquíssimas e também muito atuais vertentes da práxis política.

Pelo fato de a política educacional ser estabelecida por meio do poder de definição do processo pedagógico, em função de um grupo, de uma comunidade ou de setores dessa comunidade, ela tanto pode ser resultado de um amplo processo participativo, em que todos os membros envolvidos com a tarefa pedagógica (professores (as), alunos (as) e seus pais) debatem e opinem sobre como ela é, como deverá ser e a que fim deverá atender, como também pode ser imposição de um pequeno grupo que exerce o poder sobre a grande maioria coletiva.

Stephen Ball, entende que o estudo das políticas educacionais, por sua natureza e complexidade, poderia ser abordado através do que denominou de ciclo de políticas. No entendimento desse autor, a interlocução entre o micro e o macrossocial, proposta pelo ciclo de políticas, dá conta de uma compreensão mais apurada da realidade, pelo fato de que possibilita acompanhar uma política educacional desde sua gênese até o momento da prática. Vale dizer, o ciclo de políticas situa o foco de análise desde a formação do discurso de uma política, até a interpretação dos sujeitos que a implementam. Esse ciclo de políticas destaca a possibilidade do educador atuar como ator político. Desmistifica a ideia de que a política é feita por políticos de profissão descoladas da realidade educacional.

O autor nos chama atenção para o contexto de influência, ou seja, considerar que a educação está cada vez mais à mercê de prescrições e normas externas vinculadas à economia. Por decorrência, há um aumento da colonização das políticas educativas. Neste contingente de mudanças, insere-se a globalização. Quando falamos no contexto de prática, 
abordamos o espaço/tempo, no qual a política educacional está à mercê das interpretações e recriações dos sujeitos. As políticas educacionais não se instalam sem tensões ou negociações. As negociações poderiam suscitar o melhor entendimento dos programas, com histórias singulares, interpretações diversas, significados abertos, passíveis de várias leituras e reformulações. O pensamento dos professores e dos profissionais pode interferir na implementação das políticas, através de suas traduções e interpretações.

Os docentes envolvidos nas práticas das escolas, por vezes, desconhecem os propósitos das medidas educacionais, não tendo clareza de suas origens, finalidades ou importância. A questão que paira é que os autores dos textos não podem controlar seus efeitos e interpretações. Os textos são, portanto, resultantes de múltiplos olhares, influências e agendas, envolvendo disputas de poder. Neste sentido, a compreensão do contexto de prática se torna de fundamental importância para o estudo de políticas educacionais.

Percebemos que o contexto de criação dessas políticas depende de sujeitos que realmente se preocupem com a prática escolar, em como os professores hoje desenvolvem seu trabalho, que tenham consciência das inúmeras dificuldades enfrentadas por esses educadores, para que assim possamos ter políticas realmente eficazes no cenário educacional. A grande questão é que estamos diante de um governo com uma lógica neoliberal em que as políticas sociais são tidas como gasto público desnecessário, então, neste cenário tão nebuloso que estamos vivendo, pensar em políticas educacionais é um tema realmente muito complexo.

Dentro desse contexto a BNCC é parte da regulamentação da LDB (9.394/96), é fruto de um amplo processo de debate e negociação com diferentes atores do campo educacional e com a sociedade brasileira. Parte de grandes eixos que constituem a aprendizagem até a definição de objetivos que orientam os planos de estudos de cada disciplina. A análise da BNCC insere-se na tradição de estudos a respeito de políticas públicas na educação. No modelo democrático, este campo configura-se por uma intensa luta por participação dos segmentos envolvidos.

Em 16 de setembro de 2015, a $1^{\text {a }}$ versão da BNCC foi disponibilizada, com um texto elaborado por 116 especialistas de 35 Universidades e 2 Institutos Federais de Educação, Ciência e Tecnologia, sob coordenação do MEC. O documento, então, passa a receber sugestões pelo site da $\mathrm{BNCC}^{3}$, sendo submetido à consulta pública, para depois ser enviado ao Conselho Nacional de Educação (CNE) para obtenção de parecer.

Em 3 de maio de 2016 a $2^{\text {a }}$ versão é entregue, de 23 de junho a 10 de agosto do mesmo ano aconteceram 27 Seminários Estaduais com professores, gestores e especialistas para debater a segunda versão da BNCC. O Conselho Nacional de Secretários de Educação (Consed) e a União Nacional dos Dirigentes Municipais de Educação (Undime) promoveram esses seminários. E em abril de 2017, o MEC entrega a versão final da Base ao Conselho Nacional de Educação.

Em 20 de dezembro de 2017 a Base Nacional Comum Curricular foi homologada pelo Ministro da Educação, Mendonça Filho. Em 22 de dezembro de 2017, o CNE apresenta a Resolução CNE/CP N 2 2, DE 22 DE DEZEMBRO DE 2017 que institui e orienta a implantação da Base. Em 6 de março de 2018, educadores do Brasil inteiro se debruçaram sobre a BNCC, com foco na parte homologada do documento, correspondente às etapas da 
Educação Infantil e Ensino Fundamental, com o objetivo de compreender sua implementação e impactos na educação básica brasileira.

Em 02 de agosto de 2018, as escolas de todo o Brasil se mobilizaram para discutir e contribuir com a Base da etapa do Ensino Médio. Professores, gestores e técnicos da educação criaram comitês de debate e preencheram um formulário online, sugerindo melhorias para o documento. E assim, em 14 de dezembro de 2018, o ministro da Educação, Rossieli Soares, homologou o documento da Base Nacional Comum Curricular para a etapa do Ensino Médio. Agora, o Brasil tem uma Base com as aprendizagens previstas para toda a educação básica.

A Base se configura claramente como um cenário de disputas e entendemos que essa problematização surge de uma discussão conceitual sobre educação, formação humana, currículo e políticas curriculares. Isso, por partimos do entendimento de que o debate e as decisões sobre currículo não se esgotam na definição de determinados conteúdos ou numa ordem previamente estabelecida para que sejam abordados nas escolas.

Entendemos que o currículo ultrapassa a dimensão prescritiva dos textos de propostas que indicam objetivos, conteúdos e formas. Para além dessa dimensão prescritiva, é preciso reconhecer que por meio da palavra currículo, se expressam também o fazer propriamente dito, as ações por meio das quais se realiza o processo formativo no tempo e espaço da escola, processo esse que nem sempre vai de encontro ao que está prescrito.

Verifica-se nos debates atuais, um distanciamento entre o que é produzido como discurso curricular oficial e o que é incorporado pelas escolas, haja vista que estas reinterpretam, reelaboram e redimensionam o que é proposto. A análise de políticas curriculares impõe que se considere, assim, que o que é praticado pelas escolas não é o mero espelhamento desta ou daquela política.

Considerando o histórico da formulação da Base, as disputas são muito bem evidenciadas, sobretudo porque em seu percurso tivemos mudança de governo que anunciavam novos rumos para a educação, o que culminaria com a produção de novas Diretrizes Curriculares. Esse cenário de disputa também se evidencia quando nos deparamos com o site lançado pelo MEC no dia 30 de julho de 2015 sobre a BNCC onde, na seção Propostas Curriculares pelo Brasil é possível constatar que estamos diante de configurações muito diversas em se tratando de currículo.

Analisando esses dados, alguns questionamentos surgem inevitavelmente. É possível falar em um currículo nacional, sem cair na ideia de uma determinação que desconsidera a realidade que insiste em ser tão desigual? Quais vozes foram ouvidas na formulação dessa política e quais foram silenciadas? Quais os interesses do governo em aderir a um projeto de Base Nacional Comum Curricular? Esses questionamentos surgem porque os conflitos e tensões se evidenciam de maneira clara nesse processo.

\section{O Ensino Religioso}


O tema Ensino Religioso é um assunto que envolve práticas culturais, as quais têm por base as raízes ideológicas que foram construídas ao longo do tempo, e isso envolve o processo de colonização e de transposição cultural estabelecido entre os povos. A implantação da cultura religiosa no Brasil seguiu os mesmos princípios ideológicos de deslocamento cultural, uma vez que os portugueses implantaram uma cultura religiosa com objetivo de estabelecer a sua forma de pensar o mundo e as questões metafísicas, subjugando a cultura que fora construída pelos índios antes do processo de colonização.

Com o passar dos anos, alguns questionamentos sobre a prática de Ensino Religioso foram surgindo, trazendo reflexões que serviram como base para compreender o multiculturalismo como um fator determinante das escolhas destas práticas pedagógicas. A conscientização sobre a diversidade cultural mudou a forma de pensar da concepção religiosa e o Brasil passou a ser concebido como um país laico.

Embora o Brasil seja um país laico, alguns segmentos sociais não conseguem compreender as diversidades religiosas e, desse modo, tentam implantar a sua convicção religiosa como única e verdadeira. Esse contexto pode se estender para a escola, tendo em vista que esse espaço funciona como centro difusor de conhecimento e das ideologias que podem influenciar a forma de pensar do educando.

A aplicação do Ensino Religioso na rede pública é regida pela Lei Federal 9.475/97, que prescreve o respeito à pluralidade religiosa, própria de um país multiétnico como o Brasil. Além de estabelecer a pluralidade religiosa como parâmetro para a produção de conteúdo no Ensino Religioso, a lei supracitada determina que a disciplina seja componente curricular facultativo para o estudante, a ser ministrada nos horários normais das escolas do Ensino Fundamental. A aplicação da disciplina nesses parâmetros, no entanto, tem causado uma série de debates acadêmicos, especificamente no que concerne aos tipos de conteúdo e à qualificação docente.

No contexto escolar, a educação religiosa pode ser tendenciosa, tendo em vista que o professor assume não só a postura de um agente que constrói o conhecimento com os alunos, mas também ocupa o papel de um sujeito formador de opiniões. A neutralidade é um desafio para o professor que atua na prática pedagógica do Ensino Religioso, visto que suas raízes culturais podem influenciar na forma de pensar uma filosofia/religião na vida de seus alunos.

Neste contexto, surge a necessidade de uma problematização acerca da criação de um currículo específico para o Ensino Religioso, tendo em vista que este ensino é mais do que aparenta ser, isto é, um componente curricular em escolas. Assim, tencionar e debater a criação e inserção deste componente é trazer elementos que se ocultam em uma dialética entre a secularização e laicidade no interior de contextos históricos e culturais.

O Estado se tornou laico, o que vale dizer que ele se tornou equidistante dos cultos religiosos, sem assumir um deles como sendo uma religião oficial. Porém, movimentos políticos, sobretudo partidários, intentam definir e ocultar aspectos dogmáticos no Ensino Religioso o que o leva a se tornar problemático, tendo em vista que envolve necessário distanciamento do Estado Laico ante o particularismo próprio dos credos religiosos. Considerando que o ensino religioso é legalmente aceito como parte do currículo escolar e 
que sua elaboração é carregada de conflitos, compreendê-lo torna-se uma questão de alta complexidade e de profundo teor polêmico.

\subsection{Análise da Proposta de Ensino Religioso na BNCC}

A novidade da inclusão do ER na BNCC associa-se ao fato de que o artigo ${ }^{\circ} 33$ da LDB incumbe os sistemas de ensino da tarefa de definir conteúdos e formas de habilitação de professores de ER. Nesses termos, a LDB desobriga o Ministério da Educação de seu poder de definir os conteúdos pragmáticos para educação básica, regra para todas as demais disciplinas dos ensinos fundamental e médio, sendo o ER a única disciplina que não estava submetida a esta regra.

A BNCC fez um processo de reconhecer que ao longo de 4 séculos do período colonial e imperial devido à estreita relação entre o Estado e a Igreja, o ensino da religião na escola pública esteve a serviço dos sistemas políticos e religiosos hegemônicos com viés proselitista.

Na década de 1980, as transformações socioculturais motivaram mudanças paradigmáticas e normativas no campo educacional, que resultaram na redefinição dos fundamentos epistemológicos do ER. Sem mencionar as profundas divisões e disputas no campo religioso, a apresentação diz que, pouco a pouco, currículos para o ER foram sendo elaborados em diferentes regiões do país, bem como, projetos de formação de professores para a operacionalização dessa disciplina, visando assegurar o "conhecimento da diversidade religiosa” sem proselitismo (Brasil 2015b p. 280).

O Superior Tribunal Federal em 27 de setembro de 2017, por 6 votos a 5 julgou o ER de caráter confessional como componente curricular das escolas públicas de ensino fundamental. O ER também foi assegurado na BNCC e aprovada pelo CNE, como referência para a formulação dos currículos dos sistemas e das redes escolares estaduais e municipais e das propostas pedagógicas das instituições escolares, obedecendo o que determina a $\mathrm{CF}$, o ER será de oferta obrigatória, no horário normal de aula, porém opcional para o aluno ${ }^{4}$.

Uma preocupação não pode ser ocultada, houve grande mobilização e discussão envolvendo as várias disciplinas para que a BNCC chegasse ao texto final. No entanto, o ER não foi discutido, já que ele havia sido retirado do texto da BNCC, já que toda fundamentação era de um ER com conteúdo determinados pelo governo, fato que fere o princípio da liberdade religiosa assegurado na CF e na LDB. A surpresa foi que, com apenas 5 dias antes da votação da BNCC, o ER é reinserido pelo CNE e aprovado com a redação que anteriormente havia sido reprovada.

Segundo a BNCC, cabe ao ER tratar os conhecimentos religiosos a partir de pressupostos éticos e científicos, sem privilégio de nenhuma crença ou convicção. Isso implica abordar esses conhecimentos com base nas diversas culturas e tradições religiosas, sem desconsiderar a existência de filosofias seculares de vida, o que sabemos ser ainda hoje, um desafio para um país tão desigual, repleto de fanatismos e intolerância que a cada dia ganham mais destaques no cenário brasileiro. 
A Base apresenta o ER como uma disciplina curricular, com conteúdo determinados para todo país pelo Ministério da Educação e que abordará muitos conceitos, aspectos, assuntos e manifestações, sendo compreendido até como uma "filosofia de vida" em uma das séries do Ensino Fundamental. Não há dúvidas de que o ER promove princípios éticos e desenvolve o espírito científico, condição já comprovada pelas muitas contribuições científicas que a Igreja deixou e deixa de herança para a humanidade. No entanto, em pressupostos de uma disciplina que permeará a relação com o sagrado, para além da cognição, compreender a dimensão religiosa como construção histórico-social semeia contradições que esvaziam a relação natural com a transcendência.

Alguns questionamentos são inevitáveis a partir desse contexto apresentado. Vejamos, a BNCC está em fase de aplicação nos sistemas de Ensino Estaduais, Municipais e Particulares, que desenvolverão suas estratégias para a execução dela, e o Ensino Religioso? Esse estará a serviço de que tipo de formação? O professor do ER será uma pessoa de fé ou um "cientista social" que possa dar conta de discutir os diversos conceitos na BNCC? Em um contexto político atual, com uma "nova direita" no comando, com seus pressupostos conversadores e que claramente se declaram cristãos, como garantir que a pluralidade religiosa seja garantida e respeitada? Como podemos falar em Estado laico se temos frases como por exemplo: "O Estado é laico, mas eu sou cristão" sendo ditas por representantes diretos do governo brasileiro? Sem dúvida este é um campo de intensos debates, conflitos e principalmente questionamentos.

Candau (2010) entende o multiculturalismo como uma realidade social na qual convivem diferentes grupos culturais, e descreve uma postura crítica aos educadores que não têm uma consciência clara da problemática das relações entre escola e cultura. De acordo com a autora, os conflitos e tensões presenciados na escola devem ser abordados sem afetar a dinâmica escolar. A colocação da autora reflete o que se observa no contexto escolar mais amplo: culturas, opiniões e costumes, diversificados, não devem ser excluídos ou uniformizados. A escola é um espaço que deve ser utilizado para realizar a construção de uma relação entre as diferentes culturas, promovendo o conhecimento e o respeito com o outro.

Percebemos, dessa forma, que a elaboração do currículo de Ensino Religioso precisa ser aberta, não partindo do princípio de uma ou outra religião, mas respeitando a multiculturalidade, a diversidade e pluralidade religiosa, ou seja, um currículo multicultural abrange essa característica e valoriza a diversidade cultural do ambiente escolar. Torna-se necessário a construção de um currículo que preserve as memórias, identidades, universos simbólicos dos seus alunos, que realizem o diálogo entre esses saberes com o conhecimento produzido pela humanidade.

Por fim, acreditamos que para ampliar o olhar sobre a prática docente no Ensino Religioso se faz necessário compreender a formulação deste currículo, bem como a existência de uma real preocupação com uma educação multicultural, um currículo que tenha como objetivo uma prática que compreenda que as matrizes religiosas se diferenciam, de acordo com a cultura e experiência individual do sujeito, haja vista que o ordenamento curricular, principalmente do Ensino Religioso, não deve ser neutro ele precisa estar atento a pluralidade 
religiosa que existe hoje em nosso país e, dessa forma, envolver a todos os sujeitos de forma ampla e com reconhecimento.

\section{Considerações Finais}

Fica evidente que as políticas públicas, principalmente as políticas educacionais, são espaços de poder, disputa e articulação, principalmente para a elite dominante, cujos representantes decidem agendas políticas que muitas vezes acabam protegendo seus próprios interesses. Alguns pesquisadores da área dizem que esse é um dos maiores problemas hoje quando falamos em políticas educacionais no Brasil, as vozes que mais são ouvidas nesses processos de formulação de políticas, são de sujeitos que não vivenciam a verdadeira realidade social brasileira.

Apple (2006) contribui de forma significante neste debate quando discute acera de uma base curricular comum, porque oferece uma visão crítico-analítica sobre como os grupos com poder operam e o que eles defendem para a educação deste século. O autor denomina esses grupos como sendo "o novo bloco hegemônico".

Enquanto os neoliberais controlam o mercado de trabalho e concebem uma educação mercantilizada, os neoconservadores defendem um currículo oficial, centralizado em um conhecimento oficial e no status do professor, que agora é visto como "a” autoridade na sala de aula em termos de conhecimentos conteudistas. Alinhados à ideia de resgate e reforço da autoridade docente sobre os estudantes, os populistas autoritários que representam o fundamentalismo cristão, defendem ferrenhamente a tradição representada pela família, em oposição ao multiculturalismo, diversidade de expressões familiares, diversidade religiosa, diversidade de gênero e uma escola autoritária centrada no adulto, ou seja, um espaço educacional não democrático. Alguns projetos, hoje, deixam isso bem claro como o "Escola sem Partido" 5 , que se apresenta como um projeto que luta contra a doutrinação política e partidária em sala de aula, dizendo que muitos professores, hoje, são doutrinadores que manipulam mentes jovens em sala.

Uma vez compreendido que o currículo constitui um campo de interesses entre forças econômicas, políticas, internacionais e nacionais, cujo cerne sempre está nas relações de poder, não podemos deixar de enfatizar que no mundo o novo bloco hegemônico assume como tarefa prioritária empurrar politicas educativas em direção a práticas conservadoras fundamentadas na centralização do poder docente. Isso significa que, essas forças poderosas concebem a educação e a escola a partir de pressupostos distintos daqueles em curso no Brasil, pelo menos por enquanto, e que se fundamentam na Constituição Brasileira (Brasil, 1988) e na LDB (Brasil, 1996), documentos inspirados nos princípios de liberdade e laicidade.

Tanto a BNCC quanto a inserção do ER se configuram em um contexto de conflitos e disputas que se evidenciam de forma clara em nosso sistema político atual. Isso justifica a importância de se refletir sobre a temática e de problematizá-la, tendo em vista o cenário 
político hoje no Brasil. Interesses está sendo muito bem posicionados, discursos estão sendo neutralizados e justificados, colocando em risco a nossa democracia, os nossos direitos, a nossa liberdade. Vozes estão sendo cada vez mais silenciadas. E o principal a ser discutido aqui, o desmonte claro que a educação pública, gratuita de qualidade e laica que o Brasil vem sofrendo, com representantes que deixam claro suas intenções econômicas e conservadoras, colocando em risco o futuro e o desenvolvimento do país.

É um momento nebuloso para a educação brasileira, é um momento crítico e preocupante. Enquanto pesquisadores da área, pesquisadores em educação, temos a responsabilidade de nos aprofundarmos em tais problemáticas, de questionarmos situações que claramente colocam em risco a educação pública no Brasil. Enquanto pesquisadores em educação, é indispensável um compromisso político, no sentido de estar a serviço daqueles que são excluídos socialmente, devemos nos colocar a serviço da transformação social. Fazer pesquisa em educação é sim fazer uma militância, é problematizar questões sociais, é problematizar a realidade social na qual vivemos. Um pesquisador em educação, se propõe a este movimento, colocando o que se produz a serviço dessa mesma sociedade. Esse é o nosso papel!

\section{Notas}

1. http://basenacionalcomum.mec.gov.br/. Acesso em: 18/07/2019.

2. “O Ensino Religioso na Base Nacional Comum Curricular” Disponível em: www.educalaica.net.br/161/posicoes/oensino-religioso-na-base-nacional-comum-curricular-posicionamento/. Acesso em: 18/07/2019

3. http://basenacionalcomum.mec.gov.br. Acesso em 24/07/2019.

4. STF conclui julgamento sobre ensino religioso nas escolas públicas. Disponível em: http://www.stf.jus.br/portal/cms/verNoticiaDetalhe.asp?idConteudo=357099. Acesso em: 30/07/2019.

5. https://www.programaescolasempartido.org/.

\section{Referências}

APPLE, M. W. Endireitar a Educação: as escolas e a nova aliança conservadora. Currículo sem Fronteiras, v. 2 n $^{0}$ 1, p. 55-78, jan/jun. Madison USA, 2002.

APPLE, Michael. Reestruturação educativa e curricular e as agendas neoliberal e neoconservadora: entrevista com Michael Apple. Currículo sem Fronteiras, v. 1, n. 1, p. 5-33, jan./jun. 2001. Disponível em: http://www.curriculosemfronteiras.org/vol1iss1articles/apple.pdf.

BALL, S. J. Sociologia das políticas educacionais e pesquisa crítico-social: uma revisão pessoal das políticas educacionais e da pesquisa em política educacional. Currículo sem Fronteiras, v. 6, n. 2, p. 10-32, 2006.

BALL, S. J. Vozes/redes políticas e um currículo neoliberal global. Espaço do Currículo, v. 3, n. 1, p. 485498, mar./set. 2010b.

BALL, S. J. Reforma educacional como barbárie social: economismo e o fim da autenticidade. Práxis Educativa, Ponta Grossa, v. 7, n. 1, p. 33-52, jan./jun. 2012. 
BALL, S. J. Educação Global S.A.: novas redes políticas e o imaginário neoliberal. Ponta Grossa: UEPG, 2014.

BRASIL. Constituição (1988). Constituição da República Federativa do Brasil. Brasília, DF: Senado Federal, 1988.

Lei $n^{\circ}$ 9.394, de 20 de dezembro de 1996. Estabelece as diretrizes e bases da educação nacional. Diário Oficial da União, Brasília, DF, 23 dez. 1996.

CANDAU, V. M. (org.). Educação e Cultura (s): Questões e propostas. Petropolis, RJ: Vozes, 2010.

GONTIJO, C. M. M. Base Nacional Comum Curricular (BNCC): Comentários críticos. Revista Brasileira de Alfabetização, v. 1 n 2, p. 174-190, jul/dez. Vitória-ES. 2015

HOFLING, E. M. Estado e Políticas (Públicas) Sociais. Caderno Cedes, ano XXI, nº 55, novembro. São Paulo. 2001.

LESSARD, C. Políticas Educativas: a aplicação na prática. Editora Vozes, Petrópolis RJ, 2016.

OFFE, C. Problemas Estruturais do Estado Capitalista. Rio de Janeiro: Tempo Brasileiro, 1984.

\section{Correspondência}

Rafael Marques Gonçalves: Professor da Universidade Federal do Acre vinculado ao quadro permanente de docentes no Programa de Pós-Graduação em Educação PPGE/UFAC. Doutor em Educação pelo Programa de Pós-Graduação em Educação (ProPEd) da Universidade do Estado do Rio de Janeiro. Mestre em Educação (2012) e Pedagogo (2007) pela Universidade Federal de Juiz de Fora. Líder do Grupo de Pesquisas em Políticas, Práticas e Currículos - GpPPC.

E-mail: rafamg02@gmail.com

Talita Pereira de Almeida: Mestranda em Educação pelo Programa de Pós-Graduação em Educação (PPGE) e Bacharel em História da Universidade Federal do Acre. Bolsista CAPES.

E-mail: talita.historia2017@gmail.com

Texto publicado em Currículo sem Fronteiras com autorização dos autores 